\title{
DEMOCRACIA: CRIAÇÃO DE DIREITOS *
}

Democracy: the creation of rights

Marilena Chaui **

Resumo: Procuramos aqui marcar a diferença entre a concepção liberal da democracia como regime político e aquela que toma a democracia como uma formação social aberta aos conflitos e à criação de direitos. Essa ideia da democracia encontra dois grandes obstáculos no Brasil, quais sejam, a estrutura autoritária da sociedade brasileira e a implantação da economia política neoliberal.

Palavras-chave: Democracia. Criação de direitos. Economia política neoliberal. Sociedade autoritária.

Abstract: This article intends to mark the difference between the liberal conception of democracy as a political regime and that which considers democracy as a social formation open to conflicts as well as to the creation of rights. This idea of democracy faces two major obstacles in Brazil, namely, the authoritarian structure of Brazilian society and the implementation of a neoliberal political economy.:

Key-words: Democracy. Creation of rights. Neoliberal political economy. Authoritarian society.

\footnotetext{
* Aula inaugural da Faculdade Jesuíta de Filosofia e Teologia (FAJE) em Belo Horizonte aos 5 de março de 2018.

** Professora emérita do Departamento de Filosofia da Universidade de São Paulo. Artigo recebido em 06/11/2018 e aprovado para publicação em 15/11/2018.
} 
Cidadãos de Atenas! Como ireis agora julgar pela primeira vez um crime sangrento, ouví a lei de vosso tribunal. Sobre este Rochedo de Ares, doravante, sentar-se-á perpetuamente o tribunal que fará a raça toda dos Egeus ouvir o julgamento de todo homicídio.(...). Este rochedo é chamado de Areópago. Aqui, Respeito e seu irmão Temor, noite e dia igualmente, manterão meus cidadãos longe do crime, enquanto conservarem inalteradas as leis (...). Não mancheis a pureza das leis com a impureza de estratagemas. (...) Aqui, fundo um tribunal inviolável, sagrado, mantendo uma fiel observância para que os homens possam dormir em paz.

$\mathrm{E}$ stas palavras são pronunciadas por Atena no final da Oréstia e com elas, simbolicamente, afirma-se a invenção da política, obra dos gregos.

No mesmo espírito, nas Suplicantes, Eurípides coloca na boca dos atenienses a afirmação:

O que conserva a cidade dos homens é o nobre respeito às leis.

E também no mesmo espírito, em Da República, Cícero escreve:

A coisa pública - a res publica - é a coisa do povo; e por povo deve-se entender não um agrupamento de homens como um rebanho, mas uma assembléia numerosa de homens associados uns aos outros por sua adesão a uma mesma lei e por uma certa comunidade de interesses.

O helenista Moses Finley descreveu o nascimento da política - a "invenção da política", escreveu ele - como um acontecimento que distinguiu para sempre a Grécia e Roma em face dos grandes impérios antigos. Por que invenção? Porque gregos e romanos não dispunham de modelos, mas tiveram que inventar sua própria maneira de lidar com os conflitos e divisões sociais.

A política foi inventada quando surgiu a figura do espaço público, por meio da invenção do direito e da lei (isto é, a instituição dos tribunais) e da criação de instituições públicas de deliberação e decisão (isto é, as assembléias e os senados). Esse surgimento só foi possível porque o poder político foi separado de três autoridades tradicionais que anteriormente definiam o exercício do poder: a autoridade do poder privado ou econômico do chefe de família, de cuja vontade dependiam a vida e a morte dos membros da família, a do chefe militar e a do chefe religioso, figuras que, nos impérios antigos, estavam unificadas numa chefia única, a do rei. A política nasceu, portanto, quando a esfera privada da economia e da vontade pessoal, a esfera da guerra e a esfera do sagrado ou do saber foram separadas e o poder político deixou de identificar-se com o corpo místico do governante como pai, comandante e sacerdote, representante humano de poderes divinos transcendentes. 
A Grécia inventou a democracia: todos os homens adultos nascidos na pólis eram cidadãos com isonomia e isegoria, membros natos das assembléias e tribunais, e participantes da força militar, que se realizava sob a forma de milícia popular, isto é, dos cidadãos armados.

Roma inventou a república. A res publica ou a coisa pública era o solo de Roma, distribuído entre as famílias fundadoras da civitas, os pais fundadores ou Patres, de onde vinham os patrícios, únicos a possuir cidadania. A república era oligárquica: os homens adultos membros das famílias patrícias eram os cidadãos, isto é, membros do senado, das magistraturas e comandantes militares; a plebe, excluída da cidadania ou da participação direta no governo, fazia-se representar pelo tribuno da plebe - um patrício eleito por ela - e, por meio do plebiscito, manifestava-se diretamente a favor ou contra uma decisão do senado ou lhe fazia propostas, além de participar da força militar na qualidade de comandada.

Sabemos que há uma diferença profunda entre a concepção antiga e cristã da política e a concepção moderna, desenvolvida a partir de Maquiavel. No entanto, cabe aqui mencionar um aspecto no qual um pensador grego como Aristóteles e o inventor moderno da política, Maquiavel, estão de acordo.

De fato, Aristóteles afirma que a finalidade da política é tornar iguais os desiguais. Portanto, seu ponto de partida é a divisão social entre ricos e pobres. Por sua vez, Maquiavel afirma que toda sociedade é perpassada por uma divisão originária entre o desejo dos grandes de oprimir e comandar e o desejo do povo de não ser oprimido nem comandado. Assim, em ambos, o ponto de partida é a divisão social. Maquiavel pensa que a divisão é originária e insuperável, mas pensa a política como um trabalho ou uma lógica de ação cujo objeto é essa divisão. Ou seja, o desejo do povo é puramente negativo - não ser comandado nem ser oprimido - e cabe ao príncipe moderno dar um conteúdo positivo a esse desejo como desejo de justiça e de liberdade, o que só pode ser feito se o príncipe se aliar ao povo e jamais aos grandes.

Podemos dizer que Aristóteles foi o primeiro a ter clareza sobre a diferença entre o espaço público da política e o espaço privado dos interesses pessoais e grupais. Essa diferença o levou a distinguir entre oikonomía e politiké. De fato, oikonomía, ou seja, economia, é uma palavra grega derivada de oikós, a casa, entendida como propriedade privada do chefe de família, detentor de bens imóveis, móveis e escravos; em contrapartida, politikè, ou seja, a política, uma palavra grega derivada de pólis, a cidade ou a vida política, entendida como atividade pública a respeito dos interesses e bens da cidade e dos direitos dos cidadãos. Justamente por haver separado o publico e o privado, Aristóteles também distinguiu entre virtudes privadas e virtudes públicas, isto é, pensou numa ética pública, na qual a virtude central é a justiça. Distinguiu entre justiça do partilhável ou distributiva - que se refere à distribuição dos bens e ao problema da desigualdade 
-- e justiça do participável ou participativa - que se refere ao exercício do poder e à igualdade. Ou seja, a primeira se refere ao que pode ser dividido, distribuído, partilhado; porém a segunda se refere ao que não pode ser dividido nem distribuído, mas somente participado. Uma política é injusta, do ponto de vista distributivo, quando trata os desiguais de modo igual e justa quando trata os desiguais de modo de desigual ${ }^{1}$. A função da justiça distributiva é produzir a igualdade por que, segundo Aristóteles, a política deve levar à igualdade. A justiça participativa se refere ao que não pode ser repartido porque só pode ser participado, ou seja, refere-se ao poder político, que pertence a todos os cidadãos igualmente. Uma política é injusta, neste caso, no sentido exatamente inverso ao da justiça distributiva, isto é, quando trata desigualmente os iguais, excluindo uma parte dos cidadãos do exercício do poder. A prática democrática pertence a essa justiça. Por isso a distinção entre práxis e técnica é significativa: se a política for considerada uma técnica, isto é, uma prática reservada a especialistas, excluindo os cidadãos, ela não será politicamente ética, pois comete a injustiça quanto ao direito de igual participação no poder.

É, portanto, perfeitamente possível (e necessário) instituir uma ética pública e definir a probidade política pela realização das duas formas da justiça. É isto a ética da política e não a grosseira confusão entre espaço público e espaço privado contida na expressão "a ética na política", como se se tratasse de deslocar os valores da vida privada (as virtudes e os vícios morais da pessoa privada do governante) para a vida pública quando a política nasceu justamente para realizar a distinção entre ambas. Essa confusão entre o privado e o público nos faz deslizar para uma atitude paradoxal porque pré e pós moderna ao mesmo tempo.

A concepção pré-moderna da política considera o governante não como representante dos governados, mas de um poder mais alto (Deus, a Razão, a Lei, a Humanidade, etc), que lhe confere a soberania como poder de decisão pessoal e único. Para ser digno de governar, o dirigente deve possuir um conjunto de virtudes que atestam seu bom caráter do qual dependem a paz, a segurança e a ordem. O governante virtuoso é um espelho no qual os governados devem refletir-se, imitando suas virtudes, de maneira que o espaço público é idêntico ao espaço privado das pessoas de boa conduta e a corrupção é atribuída ao mau caráter ou aos vícios do dirigente. Por isso criticam-se os vícios do tirano e nunca se examina a tirania como instituição política.

\footnotetext{
${ }^{1}$ Tomemos um exemplo: suponha que tenha havido catástrofes naturais (seca, enchente, terremoto) e que se perderam as colheitas, havendo fome na sociedade; se for estabelecido pelo Estado que cada família receberá 20 quilos de cereais, sem que se leve em conta o tamanho da família e sem que se leve em conta que há famílias ricas, que podem importar alimentos, e famílias pobres, que não podem fazê-lo, ou que há famílias pequenas, que podem lucrar vendendo o excedente recebido, e famílias grandes para as quais a quantidade de cereais é insuficiente, a decisão é injusta por que deu o mesmo tratamento aos desiguais.
} 
Por sua vez, a concepção pós-moderna aceita a submissão da política aos procedimentos da sociedade de consumo e de espetáculo. Torna-se indústria política e dá ao marketing a tarefa de vender a imagem do político e reduzir o cidadão à figura privada do consumidor. Para obter a identificação do consumidor com o produto, o marketing produz a imagem do político enquanto pessoa privada: características corporais, preferências sexuais, culinárias, literárias, esportivas, hábitos cotidianos, vida em família, bichos de estimação. A privatização das figuras do político e do cidadão privatiza o espaço público. Por isso a avaliação ética dos governos não possui critérios próprios a uma ética pública e se torna avaliação das virtudes e vícios dos governantes; e, como no caso pré-moderno, a corrupção é atribuída ao mau caráter dos dirigentes e não à má qualidade das instituições públicas.

Em contrapartida, a concepção moderna da política funda-se na distinção entre o público e o privado - portanto, na idéia de república -, volta-se para as práticas da representação e da participação - portanto, para a idéia de democracia -, e centra seu alvo na qualidade das instituições públicas. Um exemplo contundente da concepção moderna pode ser encontrado em Espinosa que, na abertura do Tratado Político, escreve:

Uma Cidade cuja salvação depende da palavra dada por alguém e cujos assuntos, para serem bem dirigidos, exigem que seus condutores ajam lealmente, não terá a mínima estabilidade. Ao invés, para que a CIdade possa durar, as coisas públicas devem estar institucionalizadas de tal maneira que aqueles que as administram, quer se conduzam pela razão, quer pela paixão, não possam ser induzidos à má-fé ou a agir desonestamente. Pouco importa à estabilidade da Cidade o motivo interior que tenham os homens para administrar corretamente as coisas públicas, desde que sejam corretamente administradas. A liberdade de ânimo ou a fortaleza de espírito é uma virtude privada. A virtude necessária à Cidade é a segurança trazida pela boa qualidade das instituições e pelas leis.

Estamos acostumados a aceitar a definição liberal da democracia como regime da lei e da ordem para a garantia das liberdades individuais. Visto que o pensamento e a prática liberais identificam liberdade e competição, essa definição da democracia significa, em primeiro lugar, que a liberdade se reduz à competição econômica da chamada "livre iniciativa" e à competição política entre partidos que disputam eleições; em segundo, que há uma redução da lei à potência judiciária para limitar o poder político, defendendo a sociedade contra a tirania, pois a lei garante os governos escolhidos pela vontade da maioria; em terceiro, que há uma identificação entre a ordem e a potência dos poderes executivo e judiciário para conter 
os conflitos sociais, impedindo sua explicitação e desenvolvimento por meio da repressão; e, em quarto lugar, que, embora a democracia apareça justificada como "valor" ou como "bem", é encarada, de fato, pelo critério da eficácia, medida, no plano legislativo, pela ação dos representantes, entendidos como políticos profissionais, e, no plano do poder executivo, pela atividade de uma elite de técnicos competentes aos quais cabe a direção do Estado. A democracia é, assim, reduzida a um regime político eficaz, baseado na idéia de cidadania organizada em partidos políticos, e se manifesta no processo eleitoral de escolha dos representantes, na rotatividade dos governantes e nas soluções técnicas para os problemas econômicos e sociais.

Ora, há, na prática democrática e nas idéias democráticas, uma profundidade e uma verdade muito maiores e superiores ao que o liberalismo percebe e deixa perceber.

Que significam as eleições? Muito mais do que a mera rotatividade de governos ou a alternância no poder, elas simbolizam o essencial da democracia, ou seja, que o poder não se identifica com os ocupantes do governo, não lhes pertence, mas é sempre um lugar vazio que, periodicamente, os cidadãos preenchem com representantes, podendo revogar seus mandatos se não cumprirem o que lhes foi delegado para representar.

É também característica da democracia que somente nela se torne claro o princípio republicano da separação entre o público e o privado. De fato, com a idéia e a prática de soberania popular, nela se distinguem o poder e o governo - o primeiro pertence aos cidadãos, que o exercem instituindo as leis e as instituições políticas ou o Estado; o segundo é uma delegação de poder, por meio de eleições, para que alguns (legislativo, executivo, judiciário) assumam a direção da coisa pública. Em outras palavras, somente na democracia os governantes não podem identificar-se ao poder, nem apropriar-se privadamente dele.

Que significam as idéias de situação e oposição, maioria e minoria, cujas vontades devem ser respeitadas e garantidas pela lei? Elas vão muito além dessa aparência. Significam que a sociedade não é uma comunidade una e indivisa voltada para o bem comum obtido por consenso, mas, ao contrário, que está internamente dividida e que as divisões são legítimas e devem expressar-se publicamente.

Da mesma maneira, as idéias de igualdade e liberdade como direitos civis dos cidadãos vão muito além de sua regulamentação jurídica formal. Significam que os cidadãos são sujeitos de direitos e que, onde tais direitos não existam nem estejam garantidos, tem-se o direito de lutar por eles e exigi-los. É esse o cerne da democracia: a criação de direitos. E por isso mesmo, como criação de direitos, está necessariamente aberta aos conflitos e às disputas. 
O que é um direito? Um direito difere de uma necessidade ou carência e de um interesse. De fato, uma necessidade ou carência é algo particular e específico. Alguém pode ter necessidade de água, outro, de comida. Um grupo social pode ter carência de transportes, outro, de hospitais. Há tantas necessidades quanto indivíduos, tantas carências quanto grupos sociais. Um interesse também é algo particular e específico, dependendo do grupo ou da classe social. Necessidades ou carências, assim como interesses tendem a ser conflitantes porque exprimem as especificidades de diferentes grupos e classes sociais. Um direito, porém, ao contrário de necessidades, carências e interesses, não é particular e específico, mas geral e universal, válido para todos os indivíduos, grupos e classes sociais. Assim, por exemplo, a carência de água e de comida manifesta algo mais profundo: o direito à vida. A carência de moradia ou de transporte também manifesta algo mais profundo: o direito a boas condições de vida. Da mesma maneira, o interesse, por exemplo, dos estudantes exprime algo mais profundo: o direito à educação e à informação. Em outras palavras, se tomarmos as diferentes carências e os diferentes interesses veremos que sob eles estão pressupostos direitos. Mas um direito difere não apenas de necessidades, carências e interesses: ele se distingue fundamentalmente do privilégio. Este é sempre particular e jamais pode transformar-se num direito sem deixar de ser um privilégio. Enquanto necessidades, carências e interesses pressupõem direitos a conquistar, privilégios se opõem aos direitos.

Justamente porque opera com o conflito e com a criação de direitos, a democracia não se confina a um setor específico da sociedade no qual a política se realizaria - o Estado --, mas determina a forma das relações sociais e de todas as instituições, ou seja, é o único regime político que é também a forma social da existência coletiva. Ela institui a sociedade democrática. Dizemos, então, que uma sociedade - e não um simples regime de governo - é democrática quando, além de eleições, partidos políticos, divisão dos três poderes da república, respeito à vontade da maioria e das minorias, institui algo mais profundo, que é condição do próprio regime político, ou seja, quando institui direitos e que essa instituição é uma criação social, de tal maneira que a atividade democrática social realiza-se como um poder social que determina, dirige, controla e modifica a ação estatal e o poder dos governantes.

Essa dimensão criadora torna-se visível quando consideramos os três grandes direitos que definiram a democracia desde sua origem, isto é, a igualdade, a liberdade e a participação nas decisões.

A igualdade declara que, perante as leis e os costumes da sociedade política, todos os cidadãos possuem os mesmos direitos e devem ser tratados da mesma maneira. Ora, a evidência história nos ensina que a mera declaração do direito à igualdade não faz existir os iguais. Seu sentido e importância encontra-se no fato de que ela abriu o campo para a criação da igualdade 
por meio das exigências e demandas dos sujeitos sociais. Por sua vez, a liberdade declara que todo cidadão tem o direito de expor em público seus interesses e suas opiniões, vê-los debatidos pelos demais e aprovados ou rejeitados pela maioria, devendo acatar a decisão tomada publicamente. Ora, aqui também, a simples declaração do direito à liberdade não a institui concretamente, mas abre o campo histórico para a criação desse direito pela prática política. Tanto é assim que a modernidade agiu de maneira a ampliar a idéia de liberdade: além de significar liberdade de pensamento e de expressão, também passou a significar o direito à independência para escolher o ofício, o local de moradia, o tipo de educação, o cônjuge, etc. As lutas políticas fizeram com que, na Revolução Francesa de 1789, um novo sentido viesse acrescentar-se aos anteriores quando se determinou que todo indivíduo é inocente até prova em contrário, que a prova deve ser estabelecida perante um tribunal e que a liberação ou punição devem ser dadas segundo a lei. A seguir, com os movimentos socialistas, acrescentou-se à liberdade o direito de lutar contra todas as formas de tirania, censura e tortura e contra todas as formas de exploração e dominação social, econômica, cultural e política. Finalmente, o mesmo se passou com o direito à participação no poder, que declara que todos os cidadãos têm o direito de participar das discussões e deliberações públicas, votando ou revogando decisões. O significado desse direito só se tornou explícito com as lutas democráticas modernas, que evidenciaram que nele é afirmado que, do ponto de vista político, todos os cidadãos têm competência para opinar e decidir, pois a política não é uma questão técnica (eficácia administrativa e militar) nem científica (conhecimentos especializados sobre administração e guerra), mas ação coletiva, isto é, decisão coletiva quanto aos interesses e direitos da própria sociedade.

Em suma, é possível observar que a abertura do campo dos direitos, que define a democracia, explica porque as lutas populares por igualdade e liberdade puderam ampliar os direitos políticos (ou civis) e, a partir destes, criar os direitos sociais - trabalho, moradia, saúde, transporte, educação, lazer, cultura -, os direitos das chamadas "minorias" - mulheres, idosos, negros, homossexuais, crianças, índios -; o direito à segurança planetária - as lutas ecológicas e contra as armas nucleares; e, hoje, o direito contra as manipulações da engenharia genética. Por seu turno, as lutas populares por participação política ampliaram os direitos civis: direito de opor-se à tirania, à censura, à tortura, direito de fiscalizar o Estado por meio de organizações da sociedade (associações, sindicatos, partidos políticos); direito à informação pela publicidade das decisões estatais.

A sociedade democrática institui direitos pela abertura do campo social à criação de direitos reais, à ampliação de direitos existentes e à criação de novos direitos. Eis porque podemos afirmar, em primeiro lugar, que a democracia é a única sociedade e o único regime político que considera o conflito legítimo. O conflito não é obstáculo; é a constituição 
mesma do processo democrático. Essa talvez seja uma das maiores originalidades da democracia. Não só trabalha politicamente os conflitos de necessidades e de interesses (disputas entre os partidos políticos e eleições de governantes pertencentes a partidos opostos), mas procura instituí-los como direitos e, como tais, exige que sejam reconhecidos e respeitados. Mais do que isso, na sociedade democrática, indivíduos e grupos organizam-se em associações, movimentos sociais e populares, classes se organizam em sindicatos e partidos, criando um poder social que, direta ou indiretamente, limita o poder do Estado. E, em segundo lugar, que a democracia é a sociedade verdadeiramente histórica, isto é, aberta ao tempo, ao possível, às transformações e ao novo. Com efeito, pela criação de novos direitos e pela existência dos contra-poderes sociais, a sociedade democrática não está fixada numa forma para sempre determinada, ou seja, não cessa de trabalhar suas divisões, suas diferenças internas, seus conflitos e por isso, a cada passo, exige a ampliação da representação pela participação, o que leva ao surgimento de novas práticas, que garantam a participação como ato político efetivo, que aumenta a cada criação de um novo direito. Em outras palavras, só há democracia com a ampliação contínua da cidadania. Por esse motivo, a cidadania, que nas chamadas democracias liberais se define apenas pelos direitos civis, numa democracia social real, ao contrário, amplia o sentido dos direitos, abrindo um campo de lutas populares pelos direitos econômicos e sociais, opondo-se aos interesses e privilégios da classe dominante. A democracia propicia uma cultura da cidadania.

III.

Resumindo nosso percurso, podemos dizer que a democracia ultrapassa a simples idéia de um regime político identificado à forma do governo e devemos tomá-la como forma geral de uma sociedade. Sob este aspecto procuramos evidenciar que os principais traços da democracia poderiam ser assim resumidos:

1. forma sócio-política definida pelo princípio da isonomia ( igualdade dos cidadãos perante a lei) e da isegoria ( direito de todos para expor em público suas opiniões, vê-las discutidas, aceitas ou recusadas em público), tendo como base a afirmação de que todos são iguais porque livres, isto é, ninguém está sob o poder de um outro porque todos obedecem às mesmas leis das quais todos são autores (autores diretamente, numa democracia participativa; indiretamente, numa democracia representativa). Donde o maior problema da democracia numa sociedade de classes ser o da manutenção de seus princípios - igualdade e liberdade - sob os efeitos da desigualdade real; 
2. forma política na qual, ao contrário de todas as outras, o conflito é considerado legítimo e necessário, buscando mediações institucionais para que possa exprimir-se. A democracia não é o regime do consenso, mas do trabalho dos e sobre os conflitos. Donde uma outra dificuldade democrática nas sociedades de classes: como operar com os conflitos quando estes possuem a forma da contradição e não a da mera oposição?

3. forma sócio-política que busca enfrentar as dificuldades acima apontadas conciliando o princípio da igualdade e da liberdade e a existência real das desigualdades, bem como o princípio da legitimidade do conflito e a existência de contradições materiais introduzindo, para isso, a idéia dos direitos (econômicos, sociais, políticos e culturais). Graças aos direitos, os desiguais conquistam a igualdade, entrando no espaço político para reivindicar a participação nos direitos existentes e sobretudo para criar novos direitos. Estes são novos não simplesmente porque não existiam anteriormente, mas porque são diferentes daqueles que existem, uma vez que fazem surgir, como cidadãos, novos sujeitos políticos que os afirmaram e os fizeram ser reconhecidos por toda a sociedade;

4. pela criação dos direitos, a democracia surge como o único regime político realmente aberto às mudanças temporais, uma vez que faz surgir o novo como parte de sua existência e, consequentemente, a temporalidade é constitutiva de seu modo de ser;

5. única forma sócio-política na qual o caráter popular do poder e das lutas tende a evidenciar-se nas sociedades de classes, na medida em que os direitos só ampliam seu alcance ou só surgem como novos pela ação das classes populares contra a cristalização jurídico-política que favorece a classe dominante. Em outras palavras, a marca da democracia moderna, permitindo sua passagem de democracia liberal á democracia social, encontra-se no fato de que somente as classes populares e os excluídos (as "minorias") sentem a exigência de reivindicar direitos e criar novos direitos;

6. forma política na qual a distinção entre o poder e o governante é garantida não só pela presença de leis e pela divisão de várias esferas de autoridade, mas também pela existência das eleições, pois estas (contrariamente do que afirma a ciência política) não significam mera "alternância no poder", mas assinalam que o poder está sempre vazio, que seu detentor é a sociedade e que o governante apenas o ocupa por haver recebido um mandato temporário para isto. Em outras palavras, os sujeitos políticos não são simples votantes, mas eleitores. Eleger significa não só exercer o poder, mas manifestar a origem do poder, repondo o princípio afirmado pelos romanos quando inventaram a política: eleger é "dar a alguém aquilo que se possui, porque ninguém pode dar o que não tem", isto é, eleger é afirmar-se soberano para escolher ocupantes temporários do governo. 
7. uma sociedade é democrática quando, além de eleições, partidos políticos, divisão dos três poderes da república, respeito à vontade da maioria e das minorias, institui algo mais profundo, que é condição do próprio regime político, ou seja, quando institui direitos e que essa instituição é uma criação social, de tal maneira que a atividade democrática social realiza-se como uma contra-poder social que determina, dirige, controla e modifica a ação estatal e o poder dos governantes.

8. dada a relação entre direitos e defesa dos cidadãos como seres racionais, livres e responsáveis, na democracia ética e política são inseparáveis, pois ambas se voltam contra a violência (como veremos mais adiante).

Todavia, no capitalismo, são imensos os obstáculos à democracia, pois o conflito dos interesses é, na verdade, expressão do fundamento mesmo da divisão social, ou seja, a contradição entre o capital e o trabalho e, portanto, a exploração de uma classe social por outra. Assim, por exemplo, se é verdade que as lutas populares nos países do capitalismo central ou metropolitano ampliaram os direitos dos cidadãos e que a exploração dos trabalhadores diminuiu muito, sobretudo com o Estado do Bem-Estar Social, também é verdade, no entanto, que houve um preço a pagar: a exploração mais violenta do trabalho pelo capital recaiu sobre os trabalhadores dos países da periferia do sistema. Por outro lado, também é inegável, em toda parte, a fragilidade dos direitos políticos e sociais sob a ação do neoliberalismo e, portanto, do encolhimento do espaço público e alargamento do espaço privado ou do mercado, sob a forma da privatização e da chamada "desregulação econômica". Além disso, ao abandonar os investimentos dos fundos públicos nos serviços e direitos sociais e ao destinar os fundos públicos ao aumento da liquidez do capital para o desenvolvimento das novas tecnologias, o Estado neoliberal põe em risco todos os direitos econômicos e sociais conquistados pelas lutas populares.

O direito à participação política também encontra obstáculos, sob os efeitos da divisão social entre dirigentes e executantes ou a ideologia da competência técnico-científica, isto é, a afirmação de que quem possui conhecimentos está naturalmente dotado de poder de mando e direção. Iniciada na esfera da produção econômica, essa ideologia propagou-se para a sociedade inteira que vê, assim, a divisão social das classes ser sobre-determinada pela divisão entre "competentes" que, supostamente, sabem e "incompetentes" que nada sabem e apenas executam ordens. Fortalecida pelos meios de comunicação de massa que a estimulam diariamente, essa ideologia invadiu a política, que passou a ser considerada uma atividade reservada para técnicos ou 
administradores políticos competentes e não uma ação coletiva de todos os cidadãos. Dessa maneira, não só o direito à representação política (ser representante) diminui porque se restringe aos competentes, os quais, evidentemente, pertencem à classe economicamente dominante, que, assim, dirige a política segundo seus interesses e não de acordo com a universalidade dos direitos. Enfim, não podemos minimizar o obstáculo ao direito à participação política posto pelos meios de comunicação de massa, que inviabilizam o direito à informação - não só o direito de recebê-la, como ainda o de produzi-la e fazê-la circular. Na medida em que as mídias são empresas capitalistas, produzem (não transmitem) informações de acordo com os interesses privados de seus proprietários e das alianças econômicas e políticas destes com grupos detentores de poder econômico e político, criando obstáculos ao direito à verdadeira participação política.

Essa dificuldade aumenta consideravelmente quando consideramos os principais efeitos da política neoliberal. Recusando toda e qualquer correlação entre a distribuição da riqueza - o direito à igualdade - e a distribuição do poder - o direito à participação - a política neoliberal destrói a democracia como espaço da criação e conservação de direitos e como legitimidade das contradições sócio-políticas ou da luta de classes, reduzindo-a à proteção dos indivíduos contra os problemas urbanos e a delinqüência. As comunidades não são vistas como pólo de auto-organização social, nem como contra-poderes sociais e muito menos como forma de expressão das classes sociais e dos grupos, mas como perigosas para o Estado. A função do Estado é dupla: em primeiro lugar, excluir, sem danos aparentes, a idéia de vínculo entre justiça social e igualdade socioeconômica; em segundo, desobrigar-se de lidar com o problema da exclusão e da inclusão das camadas populares, desobrigando-se do "perigo" da distribuição da renda. Mas não só isso. O neoliberalismo propõe que os recursos públicos ou o fundo público seja dirigido para a acumulação e reprodução do capital e por esse motivo propõe não somente a saída do Estado da regulação da economia e do setor de produção (isto é, propõe a privatização das empresas públicas), mas também sua saída do setor de garantia dos direitos sociais (saúde, educação, moradia, cultura) transformados em serviços vendidos e comprados no mercado. Numa palavra, a privatização dos direitos sociais. O próprio Estado é concebido tendo como modelo a empresa privada e a política é definida como gestão do setor público de acordo com os padrões e critérios do mercado e não como governo da sociedade e poder público.

Dessa maneira, o neoliberalismo se caracteriza pelo alargamento do espaço privado dos interesses de mercado e o encolhimento do espaço público democrático dos conflitos e dos direitos.

Para compreendermos essa mutação histórica precisamos compreender que o neoliberalismo é a forma contemporânea do totalitarismo. De fato, 
o núcleo que define a forma totalitária é a homogeneização de todas as instituições sociais e políticas que, sendo idênticas, constituem um todo indivisível. No caso do totalitarismo neoliberal, todas as instituições sociais e políticas são consideradas organizações de um tipo determinado: a empresa. A escola, o hospital, a creche, as artes, o centro cultural, os cultos religiosos são empresas definidas pelas operações de mercado. Nessa perspectiva, Estado também é concebido como empresa e suas ações, definidas pelas regras do espaço privado, isto é, pelo mercado.

A essas dificuldades postas pelo capitalismo neoliberal precisamos acrescentar as dificuldades específicas que a sociedade brasileira coloca para a instituição de uma sociedade democrática.

De fato, nossa sociedade é marcada pelo predomínio do espaço privado sobre o público e, tendo seu centro na hierarquia familiar, é fortemente verticalizada em todos os seus aspectos: nela, as relações sociais e intersubjetivas são sempre realizadas como relação entre um superior, que manda, e um inferior, que obedece. As diferenças e assimetrias são sempre transformadas em desigualdades que reforçam a relação de mando e obediência. O outro jamais é reconhecido como sujeito nem como sujeito de direitos, jamais é reconhecido como subjetividade nem como alteridade. As relações, entre os que se julgam iguais, são de "parentesco", isto é, de cumplicidade; e, entre os que são vistos como desiguais, o relacionamento toma a forma do favor, da clientela, da tutela ou da cooptação, e, quando a desigualdade é muito marcada, assume a forma da opressão.

Nela, há a recusa tácita (e, às vezes explícita) para fazer operar o mero princípio liberal da igualdade formal e a dificuldade para lutar pelo princípio socialista da igualdade real: as diferenças são postas como desigualdades e, estas, como inferioridade natural (no caso das mulheres, dos trabalhadores, dos negros, índios, migrantes, idosos) ou como monstruosidade (no caso dos homossexuais);

Nela, há a recusa tácita (e às vezes explícita) de operar com o mero princípio liberal da igualdade jurídica e a dificuldade para lutar contra formas de opressão social e econômica: para os grandes, a lei é privilégio; para as camadas populares, repressão. A lei não deve figurar e não figura o polo público do poder e da regulação dos conflitos, nunca definindo direitos e deveres dos cidadãos porque a tarefa da lei é a conservação de privilégios e o exercício da repressão. Por este motivo, as leis aparecem como inócuas, inúteis ou incompreensíveis, feitas para serem transgredidas e não para serem transformadas. $\mathrm{O}$ poder judiciário é claramente percebido como distante, secreto, representante dos privilégios das oligarquias e não dos direitos da generalidade social.

Nela, os conflitos não são ignorados e sim recebem uma significação precisa: são considerados sinônimo de perigo, crise, desordem. Por isso, a eles se 
oferece uma única resposta: a repressão policial e militar, para as camadas populares, e o desprezo condescendente, para os opositores em geral.

Nela, está bloqueada a esfera pública da opinião como expressão dos interesses e dos direitos de grupos e classes sociais diferenciados e $\backslash$ ou antagônicos. Os meios de comunicação monopolizam a informação e o consenso é confundido com a unanimidade, de sorte que a discordância é posta como ignorância ou perigo.

Nela, é operada a naturalização das desigualdades econômicas e sociais a desigualdade salarial entre homens e mulheres, entre brancos e negros, a exploração do trabalho infantil e dos idosos são consideradas naturais; a existência dos sem-terra, dos sem-teto, dos desempregados é atribuída à ignorância, à preguiça e à incompetência dos "miseráveis"; a existência das crianças sem infância é vista como "tendência natural dos pobres à criminalidade". Do mesmo modo, há naturalização das diferenças étnicas, postas como desigualdades raciais entre superiores e inferiores, das diferenças religiosas e de gênero, bem como naturalização de todas formas visíveis e invisíveis de violência.

A sociedade brasileira está polarizada entre as carências das camadas populares e os privilégios da classe dominante e, portanto, pelo bloqueio à criação e garantia de direitos, núcleo definidor da democracia.

Endereço da Autora:

Rua Conde de Porto Alegre, 2092

04608-003 São Paulo - SP

1mschaui@gmail.com 